Article

\title{
Agricultural Drought Assessment in East Asia Using Satellite-Based Indices
}

\author{
Dong-Hyun Yoon ${ }^{1}$, Won-Ho Nam ${ }^{1,2,3, * \mathbb{C}}$, Hee-Jin Lee ${ }^{1}$, Eun-Mi Hong ${ }^{4}$, Song Feng ${ }^{5}$, \\ Brian D. Wardlow ${ }^{6,7}$, Tsegaye Tadesse ${ }^{6,8} \oplus^{(}$, Mark D. Svoboda ${ }^{6,8}{ }^{(D}$, Michael J. Hayes ${ }^{6}$ and \\ Dae-Eui Kim ${ }^{9}$ \\ 1 Department of Bioresources and Rural Systems Engineering, Hankyong National University, Anseong 17579, \\ Korea; donghyun.yoon@hknu.ac.kr (D.-H.Y.); heejin.lee@hknu.ac.kr (H.-J.L.) \\ 2 Institute of Agricultural Environmental Science, Hankyong National University, Anseong 17579, Korea \\ 3 National Agricultural Water Research Center, Hankyong National University, Anseong 17579, Korea \\ 4 School of Natural Resources and Environmental Science, Kangwon National University, Chuncheon 24341, \\ Korea; eunmi.hong@kangwon.ac.kr \\ 5 Department of Geosciences, University of Arkansas, Fayetteville, AR 72701, USA; songfeng@uark.edu \\ 6 School of Natural Resources, University of Nebraska-Lincoln, Lincoln, NE 68583, USA; \\ bwardlow2@unl.edu (B.D.W.); ttadesse2@unl.edu (T.T.); msvoboda2@unl.edu (M.D.S.); \\ mhayes2@unl.edu (M.J.H.) \\ 7 Center for Advanced Land Management Information Technologies, University of Nebraska-Lincoln, \\ Lincoln, NE 68583, USA \\ 8 National Drought Mitigation Center, University of Nebraska-Lincoln, Lincoln, NE 68583, USA \\ 9 Rural Research Institute, Korea Rural Community Corporation, Ansan 15634, Korea; dekim@ekr.or.kr \\ * Correspondence: wonho.nam@hknu.ac.kr; Tel.: +82-31-670-5137
}

Received: 17 December 2019; Accepted: 30 January 2020; Published: 1 February 2020

\begin{abstract}
Drought is the meteorological phenomenon with the greatest impact on agriculture. Accordingly, drought forecasting is vital in lessening its associated negative impacts. Utilizing remote exploration in the agricultural sector allows for the collection of large amounts of quantitative data across a wide range of areas. In this study, we confirmed the applicability of drought assessment using the evaporative stress index (ESI) in major East Asian countries. The ESI is an indicator of agricultural drought that describes anomalies in actual/reference evapotranspiration (ET) ratios that are retrieved using remotely sensed inputs of land surface temperature (LST) and leaf area index (LAI). The ESI is available through SERVIR Global, a joint venture between the National Aeronautics and Space Administration (NASA) and the United States Agency for International Development (USAID). This study evaluated the performance of ESI in assessing drought events in South Korea. The evaluation of ESI is possible because of the availability of good statistical data. Comparing drought trends identified by ESI data from this study to actual drought conditions showed similar trends. Additionally, ESI reacted to the drought more quickly and with greater sensitivity than other drought indices. Our results confirmed that the ESI is advantageous for short and medium-term drought assessment compared to vegetation indices alone.
\end{abstract}

Keywords: drought monitoring; agricultural drought; Evaporative Stress Index (ESI); satellite imagery; vegetation

\section{Introduction}

Extreme drought events in recent decades have caused extensive damage to natural ecosystems and have contributed to lower agricultural productivity all over the world [1]. As drought is one of the costliest natural disasters due to its collective impact on larger population with huge economic 
loses [2,3], the development of drought monitoring technology for rapid drought response is needed [4]. The severity of a drought is determined by how much there is precipitation in that period, compared to the average yearly precipitation. However, it is very difficult to grasp the extent of the damage as well as the timing of the beginning and end of these droughts. It is also difficult to objectively quantify drought characteristics such as intensity, geographical extent, and duration [5-8]. Therefore, in evaluating drought, the occurrence and distribution of temporal and spatial patterns should be identified [9,10], and it is important to quantify drought conditions that reflect the characteristics of drought-affected areas [11-13].

To analyze the occurrence and distribution of drought, weather, data-based drought indices have been widely used. Some of the most commonly used drought indices are the standardized precipitation index (SPI), standardized precipitation evapotranspiration index (SPEI), palmer drought severity index (PDSI), and standardized groundwater level index (SGI). All these drought indices are interpolated using the station's point data, which are then mapped to a spatial distribution. The disadvantage of using interpolated values is that they are less accurate and do not take into account topographical features. Remote exploration techniques can compensate for the disadvantages of these point data-based drought indices. Using satellite images, data can be acquired for areas that are inaccessible on the ground, as well as for a broader spatial area. The availability of satellite images for drought monitoring has been demonstrated through a number of studies [14,15]. Some of the indices based on satellite imagery, which are commonly applied for assessing drought, include the normalized difference vegetation index (NDVI), the enhanced vegetation index (EVI), the leaf area index (LAI), and the vegetation health index (VHI). The NDVI is a graphical indicator used to assess whether the target being observed contains live green vegetation or not [16]. This is derived from the visible and near-infrared reflectance (VIS-NIR) that is associated with the fraction of solar radiation absorbed by plants during photosynthesis [17]. The EVI has been shown to be well correlated with the LAI, biomass, canopy cover, and the fraction of absorbed photosynthetically active radiation [18], and therefore, is useful in monitoring seasonal, inter-annual, and long-term variation in vegetation structure. The LAI reflects the biochemical and physiological processes of vegetation, thereby indicating the productivity of vegetation, and it serves as an input variable in land-surface process models. Therefore, understanding the LAI of a crop and its dynamics is very important for a wide range of agricultural studies, such as crop growth monitoring and crop yield estimation [19]. The VHI was developed by [20] and is generated through the calculation of the vegetation condition index (VCI) and the thermal condition index (TCI). The VHI is a drought index that accounts for vegetation and temperature, and has been applied in drought detection, drought severity and duration assessment, and drought early warning systems [21]. As such, drought indices using satellite images all analyze droughts, but each one needs different factors. Depending on the factors used, the characteristics of the drought that can be determined also vary.

While vegetation-based drought indices have proved to be valuable for monitoring the general vegetation condition, they are somewhat limited in effectively characterizing the impacts of drought on vegetation [22,23]. Therefore, this study used the evaporative stress index (ESI)—a drought index based on evaporation volume-to evaluate droughts. The ESI uses the ratio of potential evapotranspiration to actual evapotranspiration. Potential evapotranspiration is the amount of evapotranspiration obtained under ideal conditions, such as when crops are healthy and there is sufficient moisture in the growth. In such a case, the maximum amount of evapotranspiration is considered. However, actual evapotranspiration is affected by various factors such as the supply of water, condition of the crops, and weather conditions, and the corresponding amount of evapotranspiration is obtained. The differences between these two factors can determine how much water is in the area, and the ESI is an indicator of drought, which is obtained by standardizing these values. Existing studies show that this index is suitable for drought detection and is more sensitive to a flash drought (rapidly occurring short term drought) compared to other indices [24]. The ESI has been used to produce drought maps for the U.S. [25] and has been compared with existing precipitation-based drought indices to test its 
applicability in detailed drought determination. In this study, we wanted to use satellite images to monitor droughts to determine which indices were more sensitive and accurate. The index (EVI, LAI) for the factors was determined as it was expected to be suitable in identifying crop damage. ESI only considers evapotranspiration. In several recent studies, its usefulness in drought determination has been verified in areas centered on the United States. In this study, we intend to review its usefulness in Asia, where little research has made use of ESI. The indices used in this study are vegetation and evaporation. VHI, which is calculated by taking both factors into account, was also added to confirm the effect of evapotranspiration on drought sensitivity. Using three kinds of indices: the Vegetation Index, the Evapotranspiration Index, and the Vegetation and Evapotranspiration Index, we identified drought trends in major East Asian countries, and confirmed that ESI is more sensitive than other indices and can be used as a drought judgement index in East Asia.

\section{Materials and Methods}

\subsection{Evaporative Stress Index (ESI)}

The ESI was established as a new drought index in which evapotranspiration is compared to potential evapotranspiration using geostationary satellite data. The ESI represents standardized anomalies in a normalized clear-sky evapotranspiration (ET) ratio where a reference ET scaling flux is used to minimize the impacts of non-moisture related drivers (e.g., seasonal variations in radiation load). We use the FAO-96 Penman-Monteith (FAO PM) reference ET [26]). Recent research compared the use of several different scaling fluxes over the continental U.S. and found that the FAO PM equation provided the best agreement with drought classifications in the U.S. Drought Monitor and with soil moisture-based drought indices $[27,28]$. By considering ETref rather than using ET alone, the impact of seasonal cycles on net radiation at the land surface can be minimized when assessing ET anomalies [29]. As discussed in Reference [30], a comparison of the observed ET flux to a reference ET flux provides a more meaningful depiction of moisture-related stress than the ET alone, because it places changes in actual ET in context with observed changes in the evaporative demand and solar radiation forcing.

The ESI is based on the remote sensing model atmosphere-land exchange inverse (ALEXI). The ALEXI model computes the ESI through a two-source energy balance model established by Reference [31] and factors (e.g., surface temperature, plants distribution, and solar radiation estimates) are considered in the thermal infrared image acquired through the geostationary operational environmental satellite (GOES). ET data sets calculated are acquired and generated daily. However, these data generated on a daily basis may differ in the data gap. This issue is partially remedied by compositing the clear-sky ET estimates and corresponding reference ET fluxes over multi-week time periods. Standardized ET fraction anomalies, expressed as pseudo z-scores normalized to a mean of 0 and a standard deviation of 1 , are then computed at weekly intervals using data composited over 2, 4, and 8 week time periods. The mean and standard deviations for each week and compositing period are computed separately for each grid point using data from 2001-2015 [32]. The ESI images provided by the GOES represent a 7-day cycle and $5 \mathrm{~km}$ resolution world images, and provide composite images of 4-week data.

The ESI is represented by anomalous values in most studies, whereby a value below -2 is indicative of drought and a value above 2 is indicative of wet conditions [33]. Values between 2 and -2 are not defined by an exact drought depth. Even in previous studies, the ESI's drought depth classification was not exactly achieved. However, values below -2 are certainly defined as drought. Accordingly, in this study, a value of -2 or less met the criteria of drought. A value below -2 was extracted from the images and used for the ESI's analysis of regional drought trends.

\subsection{Vegetation Health Index (VHI)}

$\mathrm{VHI}$ is a widely used remote sensing-based vegetation index designed as the weighted sum of two components such as VCI and TCI. It is used to identify and classify plant stresses through the 
satellite's infrared and near-infrared channels. It is calculated using the VCI and TCI for each pixel and month of a given year, where the VCI is computed according to the following equation [1]:

$$
\mathrm{VCI}=\frac{N D V I-N D V I_{\min }}{N D V I_{\max }-N D V I_{\min }}
$$

where the NDVI is the value for the pixel and month, and $N D V I_{\min }$ and $N D V I_{\max }$ are the minimum and maximum values of the NDVI over the whole period, respectively, for the considered pixel and month.

Using a similar procedure, the TCI is computed according to the following equation [2]:

$$
\mathrm{TCI}=\frac{L S T_{\max }-L S T}{L S T_{\max }-L S T_{\min }}
$$

It should be noted that Reference [34] first proposed this index based on top-of-atmosphere brightness temperatures, which are considered to be a proxy for surface temperature. Finally, the VHI is given by the following equation [3]:

$$
\mathrm{VHI}=\alpha \mathrm{VCI}+(1-\alpha) \mathrm{TCI}
$$

where $\alpha$ is a weight parameter that is usually set as 0.5 [35]. The National Oceanic and Atmospheric Administration (NOAA) satellites enable worldwide VHI images to be acquired, and available data is provided at a $4 \mathrm{~km}$ resolution over an 8-day cycle. The VHI has a dimensionless value from 0 to 100. NOAA STAR (The Center for Satellite Applications and Research) and a preceding study define a dry period when the VHI value is below 50 [36]. In addition, when the VHI value is below 30, the prevailing conditions are classified as drought. In this study, the criteria for determining drought in the VHI were selected when the index value was below 30 .

This study compares the drought index based on vegetation with the drought index based on the amount of evapotranspiration. VHI, which considers both vegetation and evapotranspiration, was added as a comparative target to determine the extent of evaporation and how they can affect drought sensitivity.

\subsection{Leaf Area Index (LAI)}

The leaf area index (LAI) is a dimensionless variable that was first defined as the total one-sided area of photosynthetic tissue per unit of ground surface area [37]. However, the LAI has different applications depending on vegetation distribution and type. If foliage elements are not flat, but wrinkled, bent, or rolled, the one-sided area cannot be clearly defined [38]. Thus, the projected leaf area has been proposed $[39,40]$. Recent research consequently defined the LAI as the maximum projected leaf area per unit of ground surface area [41]. To reflect plant characteristics, a definition of LAI and its interpretation are still proposed. Under the current literature and Watson's definition, the LAI is defined and used in half of the total leaf area per unit ground area [42-44]. The Land Processes Distributed Active Archive Center (LP DAAC) currently provides two versions of Level 4-combined Terra and Aqua MODIS LAI products: an 8-day LAI composite (MCD15A2) and a 4-day LAI composite (MCD15A3). Both the 8-day and 4-day LAI products are based on the same retrieval algorithms, and are synchronously composited with a standard scheme every 8 days and 4 days, respectively [45]. The criteria for determining droughts in the LAI were selected to dry values below 2, as described by the Level-1 and Atmosphere Archive and Distribution System (LAADS) of NASA that provided the images.

\subsection{Enhanced Vegetation Index (EVI)}

The EVI was developed to optimize the vegetation signal with improved sensitivity in high biomass regions and improved vegetation monitoring through a decoupling of the canopy background signal and a reduction in atmospheric influences [46]. Furthermore, the EVI was proposed to overcome 
the saturation problem of the NDVI, which occurs when there are a great variety of vegetation types in an area [47]. The index was developed by the inclusion of the blue reflectance band to correct for atmospheric and soil background influences [48], and is derived according to the following equation [4]:

$$
\mathrm{EVI}=\mathrm{G} * \frac{(N I R-\text { Red })}{(L+N I R+C 1 * \text { Red }-C 2 * \text { Blue })}
$$

where $\mathrm{L}$ is the canopy background adjustment factor, which is equal to 1; $\mathrm{C} 1$ and $\mathrm{C} 2$ are aerosol correction factors that are equal to 6 and 7.5, respectively; and G is the gain factor, which is equal to $2.5[49,50]$. Based on the description provided by NASA's LAADS, less than 0.2 and more than 0.08 values of EVI were selected as dry (Usually, the EVI value of healthy vegetation is more than 0.2. In addition, EVI values for water, land, and buildings were below 0.08).

In addition to the aforementioned LAI, EVI was used as an important comparator in determining agricultural drought, which is the purpose of this study. It was determined that the change in the index represented crop growth.

\subsection{Extreme Drought Events in East Asia}

In this study, we used the actual drought period to verify the drought indices. Currently, there is no data to provide a quantitative determination of drought damage. Therefore, news or reports on drought damage were investigated in each country to determine the actual status of drought. The actual drought status in 2017 was compared with the drought indices. This is because 2017 was a year of extreme drought in East Asia. In addition, a more accurate comparison was possible in South Korea as the Korea Meteorological Administration (KMA) provides detailed information on the affected areas and the duration of the 2017 drought. For China, Taiwan, and North Korea, excluding South Korea, as many news and reports as possible were examined to determine the period of the drought. The drought period here means the period of actual crop damage. Japan was excluded from the study because there was no damage caused by the recent drought. The selected status of the 2017 drought, based on the survey, is shown in Table 1.

Table 1. Historical extreme drought events in East Asia during recent years.

\begin{tabular}{ccc}
\hline Country & Drought Period & Drought Area \\
\hline \multirow{2}{*}{ South Korea } & May, 2017 & Central region (Gyeonggi-do, Jeolla-do, Chungcheong-do) \\
& June to July, 2017 & Nationwide \\
& August to September, 2017 & Southern region (Gyeongsang-do) \\
\hline \multirow{2}{*}{ North Korea } & June, 2017 & Southwestern region (Hwanghae-do) \\
& August, 2017 & Northeastern region (Hamgyeong-do) \\
\hline Taiwan & January to February, 2017 & Nationwide \\
\hline China & April to June, 2017 & Northern and Northeastern region \\
\hline
\end{tabular}

\subsection{Drought Analysis Method}

In this study, two methods were used to confirm the suitability of the ESI in determining drought conditions. In the first method, a spatial distribution drought map of 2017 was created to determine when the drought trend occurred, and then it was compared with the actual drought status to see how well it reflected the actual drought. However, quantitative analysis is not possible with such a map. Drought judgements, through spatial distribution maps, can only identify approximate trends. Therefore, further studies were conducted to determine droughts through quantitative values. In the second method, all the grid values of satellite images for each country were extracted and analyzed. The regions of each country were classified as administrative areas, or Eastern, Western, Northern, or Southern regions. In addition, only the extracted grid values were re-extracted for each index, which is extreme drought. With only these drought values, we identified drought trends in each country. The 
index that better reflected the actual drought area was then confirmed. Two methods were used to determine whether each index reflected the drought trends well.

\section{Results and Discussion}

\subsection{Analysis of Drought Trends Using Spatial Distribution Maps}

Drought indices obtained from satellite images were mapped to a spatial distribution to identify trends. The identification of the trends for each country was focused on the period identified by the actual drought trend survey. In the case of South Korea and North Korea, the trend was confirmed for April to September, in the case of China, from April to August, and in the case of Taiwan, from January to March.

Figure 1 shows the results for South Korea and North Korea. First of all, South Korea's drought trends confirmed through the spatial distribution map of each drought index are as follows. The ESI showed drought trends in Gyeonggi-do and Chungcheong-do from April, and showed drought trends across the country in May, June, and July. Even after August, a drought trend was obtained throughout the region, especially in the Southern region. In the case of the VHI, a drought trend was predicted for Gyeonggi-do and Chungcheong-do starting mid-May. It then deepened in June and July, showing a drought trend throughout the region. Since August, drought has tended to ease in most areas except Gyeonggi-do. In the case of the LAI and EVI, the overall drought trend was shown in April, and the index value generally increased from May to August. The LAI, however, tended to become drier from May to August in Gyeonggi-do and Chungcheong-do compared to other regions.

The drought trend in North Korea is as follows. The ESI showed drought trends in the Western region (Hwanghae-do) starting in early April. In May and June, drought in the Western region (Hwanghae-do) became more severe, and in July, drought trends were observed in all the regions. Since August, drought has gradually shown a tendency to abate, but the Northeast region (Hamgyeong-do) has shown a trend of drought. In the case of the VHI, drought trends were seen in the Western and Northern regions in April. From May to July, drought trends in the Western part of the country intensified, and drought trends appeared throughout the region. After August, the drought tended to ease in the entire region. The LAI exhibited a dry trend in April. Later, there was no drought trend in the entire region, but the Western region (Hwanghae-do) showed a dry trend with lower index values compared to other regions. For the EVI, the index was slightly lower in April, but did not show a drought trend in the overall period.

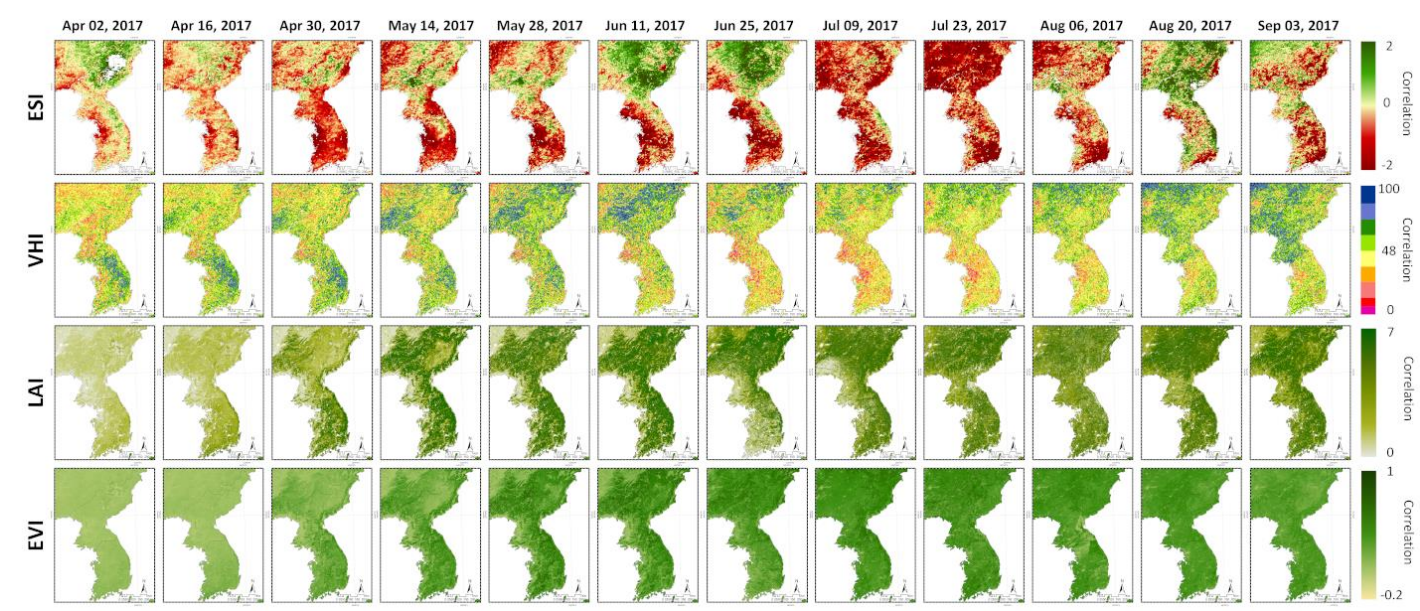

Figure 1. Comparison of trends for each drought index for South Korea and North Korea.

Figure 2 shows a map of Taiwan's spatial distribution acquired through each index. In the case of the ESI, drought trends were obtained for all regions in January and February. However, the northern regions showed a somewhat weaker drought trend compared to other regions. After February, the 
drought showed a tendency to ease. In the case of the VHI, the drought trend was only in the Western and Eastern regions from January to March, especially in the Western regions. The LAI showed a much drier trend from January to March than in other parts of the Western region and also in the Northern and Eastern regions in March. For the EVI, there are slight differences in index values between regions, but no particular tendency towards drought.

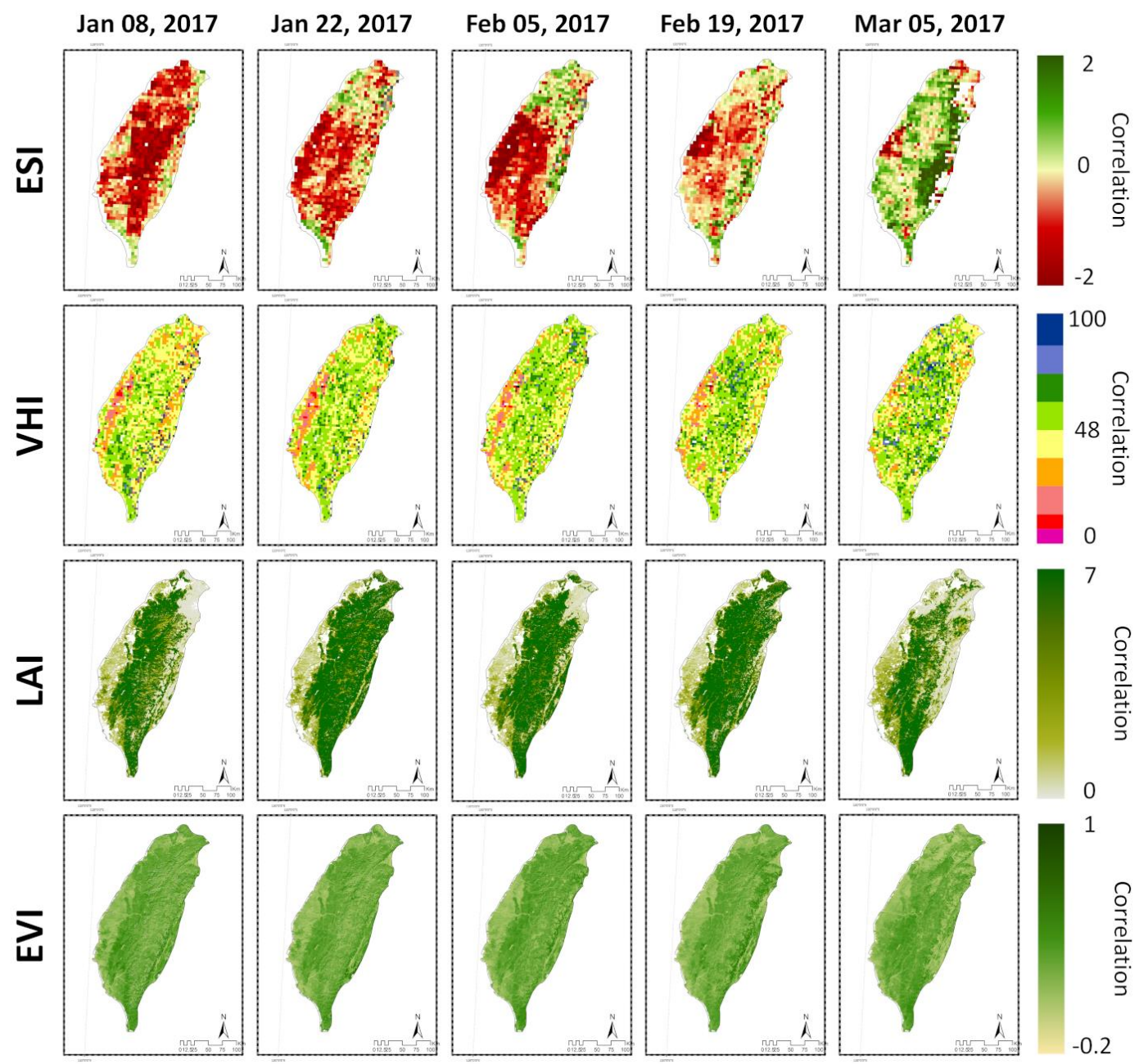

Figure 2. Comparison of trends for each drought index for Taiwan.

Figure 3 shows a map of China's spatial distribution obtained with each index. The ESI had a severe drought trend in the Northern and Northeastern regions since late April. In June and July, there was a severe drought trend in the northeastern region, and in August, there was an easing trend. In the case of the VHI, drought trends were observed in the Northern and Northeastern regions in April and May. The Northern part of the country showed severe drought trends until June and July, while the Northeastern part of the country showed a tendency of easing drought after July. The LAI and EVI all showed dry tendencies except for the southern regions until May, with vegetation growing rapidly in the Northeast since July. 



Figure 3. Comparison of trends for each drought index for China. 


\subsection{Analysis of Drought Distribution by Region by Extracting Satellite Image Grid Value}

The spatial distribution map identified the approximate trend. All the grid values of the satellite images were then extracted for each index for quantitative analysis. The percent area of the drought was calculated by extracting values below the drought standard for each index. The coloring period of the table represents the actual drought period investigated in this study. The periods shown in bold letters in the table indicate the drought periods identified by satellite images. By comparing the two periods, we confirmed how well the determination of droughts through satellite images really understood the actual drought.

Figure 4 and Table 2 show the drought rate in South Korea. In the case of ESI, the ratio of drought increased sharply in Gyeonggi-do and Chungcheong-do in April. Unlike other regions, Gyeongsang-do had a high drought rate even after July. In the case of the VHI, the overall rate of drought started increasing in June, but has exhibited a reducing trend since August. Among them, there were high drought rates, especially in Gyeonggi-do and Chungcheong-do. The LAI and EVI had very high drought rates before April. From April to September, the drought rate drops sharply. After September, the drought rate increases again. Unlike the EVI, which shows no particular trend, the LAI had higher drought rates than other regions from April to September in Chungcheongnam-do, Jeolla-do, and Gyeonggi-do. The trend of the corresponding results was significantly similar to that of the preceding study [51], which conducted drought assessment using the SPI drought index. The results of the preceding study were significantly similar to the drought trends seen by ESI and VHI. In particular, drought onset periods and drought change flows were very similar to ESI.

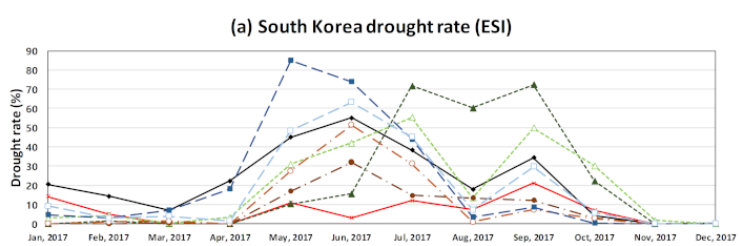

(c) South Korea drought rate (LAI)

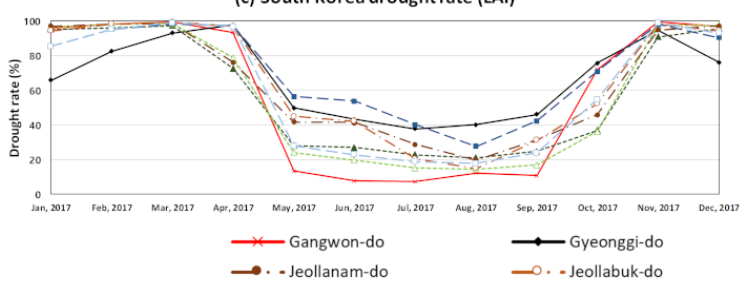

(b) South Korea drought rate (VHI)

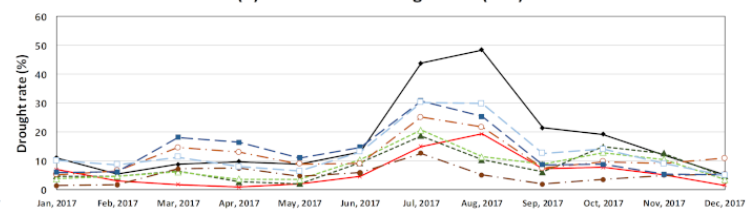

(d) South Korea drought rate (EVI)

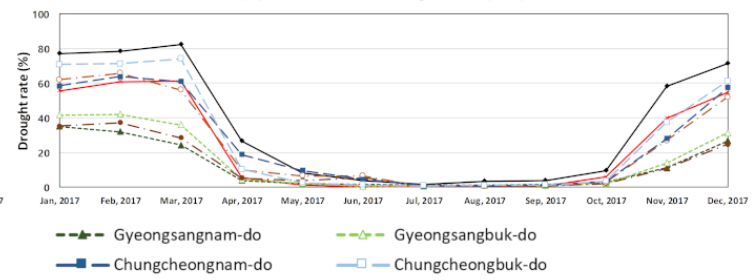

Figure 4. Temporal changes in drought area ratios of total area in each district as determined by the (a) ESI, (b) VHI, (c) LAI, and (d) EVI values for the eight provinces in South Korea during the 2017 drought. 
Table 2. Comparison of drought rate by region and actual drought periods, South Korea, 2017 (\%).

\begin{tabular}{|c|c|c|c|c|c|c|c|c|c|c|c|c|c|}
\hline Region & Index & Jan & Feb & Mar & Apr & May & Jun & Jul & Aug & Sep & Oct & Nov & Dec \\
\hline \multirow{4}{*}{ Gangwon-do } & ESI & 14.3 & 5.1 & 0.0 & 0.0 & 11.1 & 3.2 & 12.0 & 7.5 & 21.2 & 7.1 & 0.0 & 0.5 \\
\hline & VHI & 7.0 & 2.9 & 1.7 & 0.9 & 2.1 & 4.6 & 15.0 & 19.3 & 7.3 & 7.8 & 5.1 & 1.5 \\
\hline & LAI & 95.8 & 98.3 & 99.7 & 93.4 & 13.3 & 7.6 & 7.2 & 12.1 & 10.6 & 72.0 & 99.4 & 96.9 \\
\hline & EVI & 55.8 & 61.0 & 61.4 & 5.7 & 1.3 & 0.5 & 0.4 & 0.6 & 0.7 & 5.8 & 39.9 & 54.6 \\
\hline \multirow{4}{*}{ Gyeonggi-do } & ESI & 20.6 & 14.4 & 7.0 & 22.4 & 45.1 & 55.2 & 38.3 & 18.0 & 34.4 & 4.2 & 0.0 & 0.3 \\
\hline & VHI & 11.0 & 5.4 & 8.8 & 9.7 & 8.9 & 13.1 & 43.8 & 48.5 & 21.4 & 19.2 & 12.0 & 5.2 \\
\hline & LAI & 65.9 & 82.4 & 92.9 & 97.6 & 49.7 & 43.2 & 37.7 & 40.1 & 46.1 & 75.7 & 94.7 & 76.0 \\
\hline & EVI & 77.1 & 78.4 & 82.5 & 26.7 & 8.3 & 3.8 & 1.4 & 3.4 & 3.8 & 9.5 & 58.4 & 71.5 \\
\hline \multirow{4}{*}{ Gyeongsang-do } & ESI & 1.5 & 2.9 & 0.2 & 1.7 & 20.7 & 28.9 & 63.5 & 36.8 & 61.0 & 26.3 & 0.9 & 0.0 \\
\hline & VHI & 4.2 & 4.6 & 6.4 & 3.2 & 2.8 & 9.9 & 19.7 & 10.9 & 7.5 & 13.9 & 11.5 & 4.1 \\
\hline & LAI & 95.8 & 97.1 & 98.0 & 75.6 & 26.1 & 23.3 & 18.9 & 17.7 & 20.8 & 36.5 & 94.2 & 96.6 \\
\hline & EVI & 38.4 & 37.1 & 30.1 & 4.2 & 2.1 & 1.0 & 0.8 & 1.1 & 1.1 & 2.5 & 12.6 & 29.0 \\
\hline \multirow{4}{*}{ Jeolla-do } & ESI & 0.0 & 0.5 & 1.0 & 0.0 & 22.2 & 41.7 & 23.0 & 7.2 & 9.8 & 2.9 & 0.0 & 0.0 \\
\hline & VHI & 3.3 & 4.1 & 10.9 & 10.2 & 6.7 & 7.5 & 18.9 & 13.4 & 4.7 & 6.6 & 7.0 & 8.2 \\
\hline & LAI & 95.7 & 98.3 & 98.9 & 86.4 & 43.2 & 41.8 & 24.5 & 17.2 & 31.4 & 49.0 & 96.6 & 95.8 \\
\hline & EVI & 48.6 & 51.5 & 42.3 & 7.6 & 5.2 & 5.9 & 0.5 & 0.7 & 0.8 & 2.4 & 18.8 & 38.3 \\
\hline \multirow{4}{*}{ Chungcheong-do } & ESI & 7.0 & 3.1 & 5.6 & 10.0 & 66.6 & 68.6 & 44.5 & 5.5 & 19.2 & 3.0 & 0.0 & 0.0 \\
\hline & VHI & 8.0 & 7.4 & 14.7 & 12.2 & 8.7 & 14.0 & 30.6 & 27.6 & 10.6 & 11.4 & 7.2 & 5.0 \\
\hline & LAI & 85.4 & 95.2 & 98.6 & 97.0 & 42.1 & 38.2 & 29.5 & 22.7 & 33.1 & 62.8 & 98.5 & 91.7 \\
\hline & EVI & 64.7 & 67.6 & 67.5 & 14.5 & 6.1 & 2.9 & 0.7 & 1.0 & 1.2 & 3.3 & 32.7 & 59.4 \\
\hline
\end{tabular}

Figure 5 and Table 3 show the drought rate in North Korea. In the case of the ESI, drought rates increased across the entire region in July and September, especially in Hwanghaenam-do, where drought rates were high in June and July. In the case of the VHI, the rate of drought was relatively high in March, April, and July. While drought rates in other regions decreased, the rate of drought increased sharply in May, June, and July in Hwanghae-do. The LAI and EVI saw their drought rates drop to near zero as of April and March, respectively. It has since shown a tendency to increase again since August and November. However, Hwanghaenam-do had a high drought rate from June to August according to the LAI, which was quite different from those in other areas. The trend of corresponding results was significantly similar to that of the preceding study [52], which conducted drought assessment through precipitation. The results of the study were compared with those of previous studies for Korea. As a result, in the case of South Korea and North Korea, ESI and VHI results from this study and the SPI results from preceding studies showed high similarity.
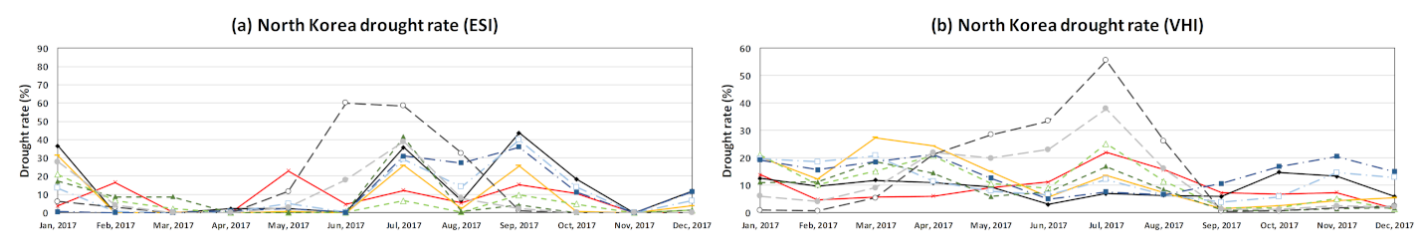

(c) North Korea drought rate (LAI)

(d) North Korea drought rate (EVI)
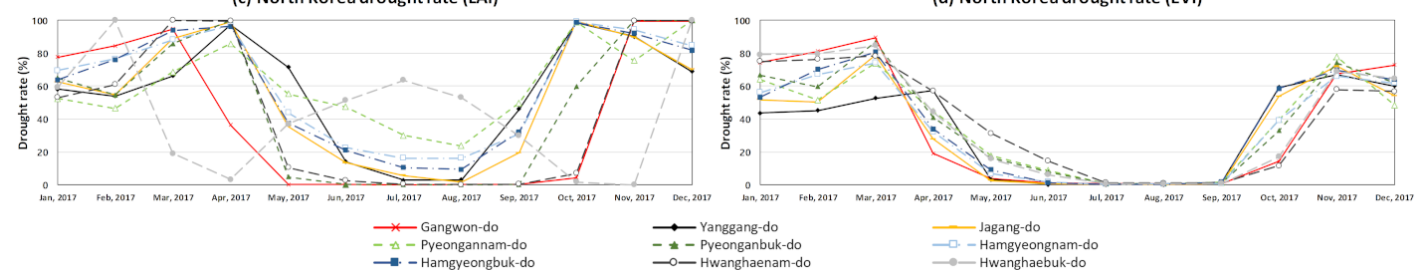

$\underset{\text { - Yanggang-do }}{\longrightarrow-\text { Pyeonganbuk-do }}$
$\rightarrow 0-$ Hwanghaenam-do

- Jagang-do

- Hamgyeongnam-do
- Hwanghaebuk-do

Figure 5. Temporal changes in drought area ratios of total area in each district as determined by the (a) ESI, (b) VHI, (c) LAI, and (d) EVI values for the nine provinces in North Korea during the 2017 drought event. 
Table 3. Comparison of drought rate by region and actual drought periods, North Korea, 2017 (\%).

\begin{tabular}{|c|c|c|c|c|c|c|c|c|c|c|c|c|c|}
\hline Region & Index & Jan & Feb & Mar & Apr & May & Jun & Jul & Aug & Sep & Oct & Nov & $\overline{\text { Dec }}$ \\
\hline \multirow{4}{*}{ Gangwon-do } & ESI & 3.7 & 16.5 & 0.2 & 0.0 & 22.8 & 4.6 & 12.3 & 5.3 & 15.4 & 10.6 & 0.0 & 0.0 \\
\hline & VHI & 13.8 & 4.7 & 5.6 & 6.0 & 9.2 & 11.1 & 21.9 & 15.6 & 7.2 & 6.7 & 7.3 & 1.5 \\
\hline & LAI & 77.7 & 84.4 & 94.9 & 36.4 & 0.1 & 0.0 & 0.0 & 0.0 & 0.0 & 4.4 & 99.5 & 99.7 \\
\hline & EVI & 74.3 & 81.3 & 89.4 & 19.0 & 4.0 & 1.1 & 0.5 & 0.9 & 0.7 & 14.1 & 67.3 & 72.8 \\
\hline \multirow{4}{*}{ Yanggang-do } & ESI & 36.5 & 0.0 & 0.0 & 2.2 & 2.2 & 0.3 & 35.6 & 6.6 & 43.6 & 18.3 & 0.0 & 11.8 \\
\hline & VHI & 12.5 & 9.8 & 11.8 & 10.9 & 9.3 & 3.0 & 6.9 & 6.2 & 5.9 & 14.7 & 13.2 & 5.9 \\
\hline & LAI & 58.2 & 54.0 & 66.3 & 97.5 & 71.5 & 13.9 & 2.7 & 2.9 & 45.9 & 98.5 & 90.2 & 68.9 \\
\hline & EVI & 43.7 & 45.2 & 52.5 & 57.5 & 3.2 & 0.3 & 0.2 & 0.2 & 1.5 & 59.3 & 67.2 & 60.0 \\
\hline \multirow{4}{*}{ Jagang-do } & ESI & 31.2 & 0.0 & 0.2 & 0.0 & 0.7 & 0.0 & 25.8 & 2.3 & 25.7 & 0.7 & 0.0 & 3.7 \\
\hline & VHI & 20.3 & 12.2 & 27.4 & 24.3 & 15.0 & 5.8 & 13.5 & 7.4 & 1.5 & 2.4 & 4.4 & 5.4 \\
\hline & LAI & 62.4 & 54.8 & 89.1 & 99.1 & 35.5 & 13.4 & 5.6 & 1.7 & 19.5 & 99.7 & 89.7 & 70.2 \\
\hline & EVI & 51.6 & 50.1 & 78.9 & 27.9 & 2.5 & 0.5 & 0.3 & 0.3 & 0.6 & 53.7 & 72.1 & 54.3 \\
\hline \multirow{4}{*}{ Pyeongan-do } & ESI & 19.1 & 7.7 & 5.4 & 0.0 & 0.0 & 0.3 & 24.0 & 0.4 & 6.8 & 2.3 & 0.0 & 1.3 \\
\hline & VHI & 16.1 & 10.7 & 16.8 & 17.6 & 8.2 & 8.2 & 20.9 & 9.9 & 1.2 & 1.2 & 3.3 & 1.4 \\
\hline & LAI & 58.6 & 50.5 & 77.2 & 92.9 & 30.1 & 23.8 & 15.0 & 11.9 & 24.9 & 79.5 & 87.7 & 99.9 \\
\hline & EVI & 65.3 & 55.6 & 80.2 & 43.0 & 17.1 & 8.2 & 0.7 & 0.7 & 1.3 & 36.1 & 76.0 & 55.3 \\
\hline \multirow{4}{*}{ Hamgyeong-do } & ESI & 6.9 & 0.2 & 0.0 & 0.6 & 3.5 & 0.1 & 30.1 & 20.6 & 37.9 & 12.6 & 0.0 & 8.9 \\
\hline & VHI & 19.4 & 17.1 & 19.7 & 16.3 & 10.3 & 5.8 & 9.8 & 6.6 & 7.2 & 11.3 & 17.5 & 13.9 \\
\hline & LAI & 66.6 & 76.3 & 91.0 & 96.5 & 40.6 & 21.8 & 13.2 & 12.8 & 31.6 & 98.9 & 93.3 & 83.2 \\
\hline & EVI & 54.7 & 68.7 & 77.4 & 33.1 & 7.9 & 1.5 & 0.4 & 0.6 & 1.2 & 48.9 & 67.9 & 62.9 \\
\hline \multirow{4}{*}{ Hwanghae-do } & ESI & 16.9 & 3.5 & 0.0 & 0.0 & 7.3 & 38.9 & 48.6 & 20.1 & 1.6 & 0.0 & 0.0 & 0.0 \\
\hline & VHI & 3.4 & 2.3 & 7.2 & 21.6 & 24.2 & 28.2 & 46.7 & 21.1 & $\begin{array}{l}0.9 \\
\end{array}$ & 0.9 & 2.1 & 2.2 \\
\hline & LAI & 56.2 & 80.4 & 59.5 & 51.4 & 23.8 & 26.9 & 32.0 & 26.6 & 15.0 & 4.3 & 50.0 & 99.9 \\
\hline & EVI & 77.1 & 78.0 & 81.5 & 50.7 & 23.4 & 10.2 & 0.8 & 0.8 & 0.9 & 14.4 & 63.4 & 60.7 \\
\hline
\end{tabular}

Figure 6 and Table 4 show the drought rate in Taiwan. In the case of the ESI, the country had a high drought rate in January. The drought rate also increased from August to October, especially in the central and Eastern regions. In the case of the VHI, there was a high drought rate in the Western region in January and a high drought rate in the central, Eastern, and Northern regions in June. Overall, the LAI and EVI exhibited no significant changes in the rate of drought. However, the EVI had a somewhat higher drought rate than other periods in January, and the LAI had a higher drought rate in the Western region over the entire period.

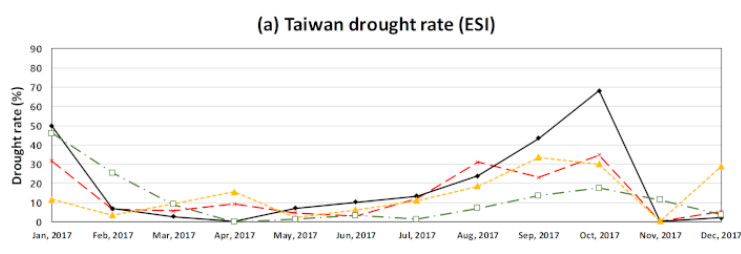

(c) Taiwan drought rate (LAI)

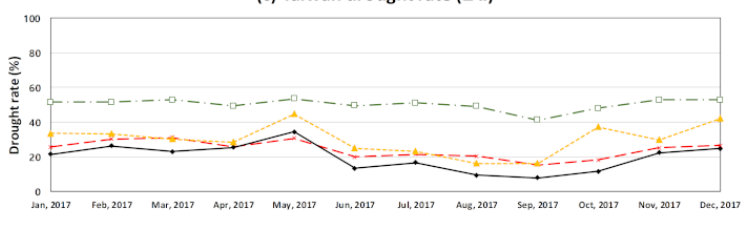

$-x-$ southern

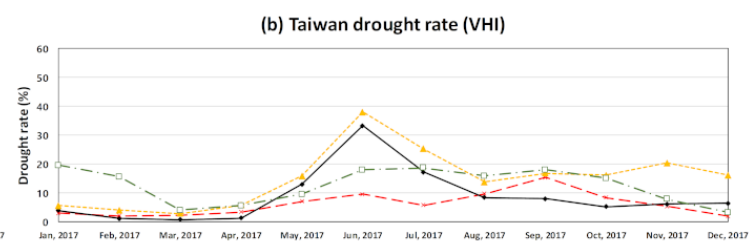

(d) Taiwan drought rate (EVI)

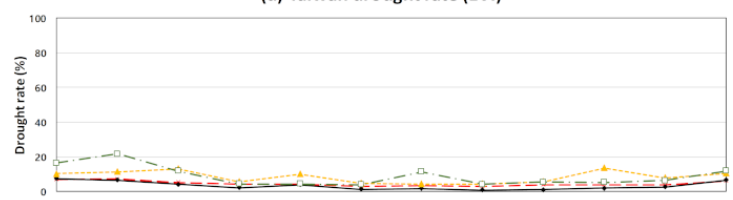

$\rightarrow-$ Western

Figure 6. Temporal changes in drought area ratios of total area in each district as determined by the (a) ESI, (b) VHI, (c) LAI, and (d) EVI values for the four regions in Taiwan during the 2017 drought event. 
Table 4. Comparison of drought rate by region and actual drought periods, Taiwan, 2017 (\%).

\begin{tabular}{|c|c|c|c|c|c|c|c|c|c|c|c|c|c|}
\hline Region & Index & Jan & Feb & Mar & Apr & May & Jun & Jul & Aug & Sep & Oct & Nov & Dec \\
\hline \multirow{3}{*}{ Southern } & ESI & 31.5 & 6.6 & 5.6 & 9.2 & 4.7 & 2.8 & 12.0 & 31.0 & 23.1 & 34.7 & 0.3 & 5.4 \\
\hline & VHI & 2.9 & 2.1 & 2.4 & 3.3 & 7.0 & 9.5 & 5.7 & 9.7 & 15.3 & 8.4 & 5.4 & 1.9 \\
\hline & LAI & 25.7 & 30.3 & 31.2 & 25.9 & 30.8 & 19.9 & 21.4 & 20.4 & 15.2 & 18.2 & 25.2 & 26.6 \\
\hline \multirow[b]{3}{*}{ Eastern and Central } & ESI & 49.6 & 6.8 & 2.7 & 0.4 & 7.1 & 10.2 & 13.4 & 23.8 & 43.5 & 68.2 & 0.4 & 2.1 \\
\hline & VHI & 3.9 & 1.1 & 0.7 & 1.3 & 13.0 & 33.3 & 17.3 & 8.4 & 7.9 & 5.2 & 6.2 & 6.5 \\
\hline & LAI & 21.5 & 26.3 & 22.9 & 25.3 & 34.4 & 13.4 & 16.6 & 9.3 & 7.9 & 11.6 & 22.2 & 24.7 \\
\hline \multirow{3}{*}{ Northern } & VHI & 5.6 & 4.0 & 2.9 & 5.8 & 15.9 & 38.0 & 25.3 & 13.7 & 16.8 & 16.2 & 20.4 & 16.1 \\
\hline & LAI & 33.5 & 33.3 & 30.2 & 28.5 & 44.7 & 24.9 & 23.3 & 16.2 & 16.2 & 37.2 & 29.9 & 42.1 \\
\hline & EVI & 10.2 & 11.3 & 13.1 & 5.6 & 10.0 & 4.7 & 4.3 & 4.3 & 5.7 & 13.5 & 7.8 & 10.5 \\
\hline \multirow{2}{*}{ Western } & ESI & 45.9 & 25.3 & 9.1 & 0.0 & 1.4 & 3.2 & 1.4 & 7.1 & 13.5 & 17.6 & 11.5 & 3.7 \\
\hline & VHI & 19.5 & 15.7 & 4.0 & 5.6 & 9.6 & 17.9 & 18.6 & 15.9 & 18.1 & 15.1 & 7.8 & 3.2 \\
\hline
\end{tabular}

Figure 7 and Table 5 show the drought rate in China. In the case of the ESI, there were relatively high drought rates in the Western region of the country in January to March, and in May and in July in the Northeastern region. In the case of the VHI, there was no significant change in the rate of drought, but the northern and eastern regions had high overall drought rates until July. In the case of the LAI and EVI, drought rates have fallen sharply since March and have shown a tendency to rise again since September.


(c) China drought rate (LAI)

(d) China drought rate (EVI)
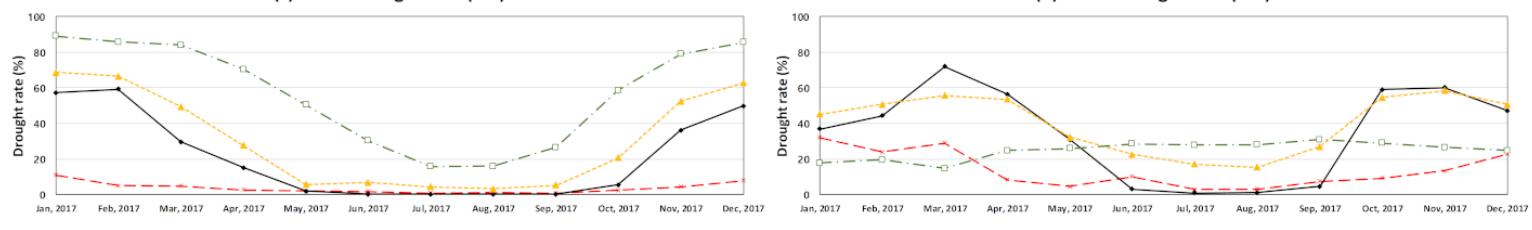

$\rightarrow \times$-Southern

$\longrightarrow$ Eastern

--1--- Northern

$\longrightarrow$ - - Western

Figure 7. Temporal changes in drought area ratios of total area in each district as determined by the (a) ESI, (b) VHI, (c) LAI, and (d) EVI values for the four regions in China during the 2017 drought event. 
Table 5. Comparison of drought rate by region and actual drought periods, China, 2017 (\%).

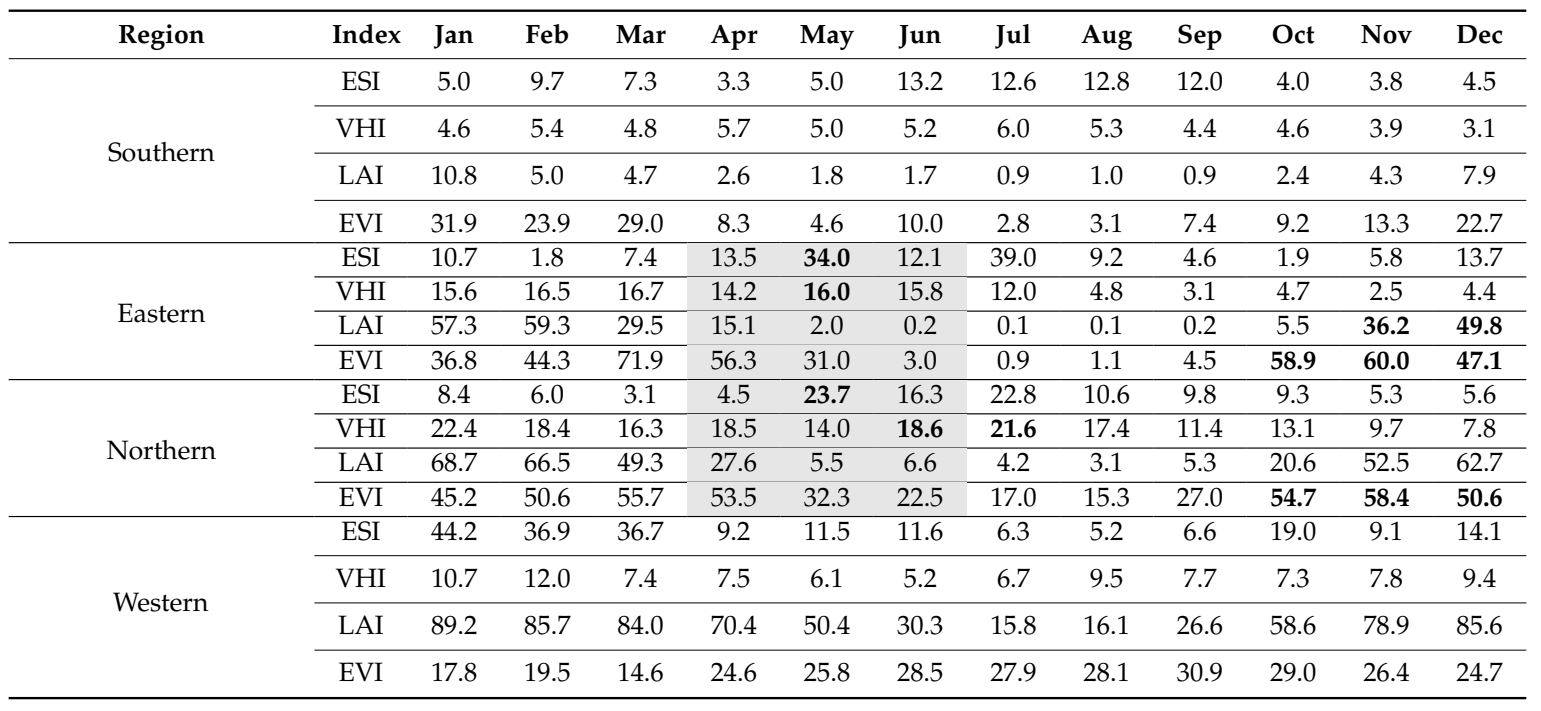

\section{Conclusions}

In this study, the use of satellite images was used to advance the limits of the ground data-based drought index, which is a traditional method for predicting droughts. Among the various satellite image drought indices, the ESI was examined with regard to usability. To check the ESI's drought judgment, an actual predicted drought was investigated. In addition, the VHI, EVI, and LAI were compared to identify differences between the ESI and other drought indices. Currently, it is not possible to determine when, where, and how much damage a drought has caused. Therefore, the judgment in this study was made only during certain periods of drought that were obtained through the survey. For the ESI, all four countries had high drought rates at the same time as the actual drought period. Furthermore, drought areas and non-drought areas were well separated. In particular, for South Korea and North Korea, drought trends emerged faster than the actual drought period. The VHI also generally reflected actual drought period and regions. However, it was difficult to determine the droughts in South Korea and North Korea that lasted beyond the rainy season. In addition, in Taiwan, there was a drought trend in the Western part of the country that could not be easily explained. In the case of the LAI, drought trends were observed in North Korea and Taiwan, but overall, the drought judgment was poor in all four countries. The EVI also showed differences in the rate of drought during several periods, but did not fit well with the actual state of drought. Drought trends have not been well identified with the LAI and EVI because the two indices were largely affected by vegetation conditions. In fact, they exhibited a very high rate of drought during the winter, but a low rate of drought in spring and summer. Among the four indices, those that reflected drought trends were the ESI and VHI, with the ESI reflecting actual drought conditions with the greatest sensitivity. While the VHI, LAI, and EVI are all based on vegetation, this difference is understood to have occurred with the ESI because vegetation data is used as a factor, but the central factor is evapotranspiration. This is because it is less affected by plant growth and can identify an immediate lack of water through differences in evapotranspiration.

In this study, we checked the suitability of drought judgments using satellite images. When monitoring and judging drought, it is important to know how sensitive the index is to drought and how well one can identify areas where drought occurred. In this context, the ESI was able to identify droughts more sensitively and accurately than other indices. The existing drought index was less accurate because it utilized space interpolation. However, the ESI is expected to help determine droughts in small administrative areas, as well as uncounted areas. Future research on the ESI's resolution improvement and crop cultivation areas is expected to help identify overall drought trends, as well as the actual size and location of drought damage. 
Author Contributions: Conceptualization, D.-H.Y., W.-H.N., B.D.W., T.T. and M.D.S.; data curation, D.-H.Y., and H.-J.L.; funding acquisition, W.-H.N.; investigation, D.-H.Y.; methodology, D.-H.Y., W.-H.N., M.D.S. and M.J.H.; project administration, W.-H.N., E.-M.H. and D.-E.K.; validation, W.-H.N.; writing-original draft, D.-H.Y.; Writing-review \& editing, W.-H.N., E.-M.H., S.F., B.D.W., T.T., M.D.S. and M.J.H. All authors have read and agreed to the published version of the manuscript.

Funding: This research was supported by the Korea Institute of Planning and Evaluation for Technology in Food, Agriculture, Forestry and Fisheries (IPET) through the Advanced Production Technology Development Program, funded by the Ministry of Agriculture, Food and Rural Affairs (MAFRA) (318060-3). This research was also supported by a grant (2019-MOIS31-010) from the Fundamental Technology Development Program for Extreme Disaster Response funded by the Korean Ministry of Interior and Safety (MOIS). The views expressed in this study are those of the authors and do not necessarily reflect the views of IPET, MAFRA, MOIS, or any of its subagencies.

Conflicts of Interest: The authors declare no conflicts of interest. The views expressed in this paper are those of the authors and do not necessarily reflect the views of IPET, MAFRA, MOIS or any of its sub-agencies.

\section{References}

1. Sevanto, S. Drought impacts on phloem transport. Curr. Opin. Plant Biol. 2018, 43, 76-81. [CrossRef] [PubMed]

2. Lott, N.; Ross, T. Tracking and Evaluating U.S. Billion Dollar Weather Disasters, 1980-2005; National Oceanic and Atmospheric Administration's National Climatic Data Center: Asheville, NC, USA, 2010.

3. Tadesse, T.; Brown, J.F.; Hayes, M.J. A new approach for predicting drought-related vegetation stress: Integrating satellite, climate, and biophysical data over the U.S. central plains. ISPRS J. Photogram. Remote Sens. 2005, 59, 244-253. [CrossRef]

4. Otkin, J.A.; Anderson, M.C.; Hain, C.; Svoboda, M. Examining the relationship between drought development and rapid changes in the Evaporative Stress Index. J. Hydrometeorol. 2014, 15, 938-956. [CrossRef]

5. Vicente-Serrano, S.M.; Beguería, S.; López-Moreno, J.I. A multi-scalar drought index sensitive to global warming: The Standardized Precipitation Evapotranspiration Index. J. Clim. 2010, 23, 1696-1718. [CrossRef]

6. Bajgain, R.; Xiao, X.; Wagle, P.; Basara, J.; Zhou, Y. Sensitivity analysis of vegetation indices to drought over two tallgrass prairie sites. ISPRS J. Photogramm. Remote Sens. 2015, 108, 151-161. [CrossRef]

7. Bajgain, R.; Xiao, X.; Basara, J.; Wagle, P.; Zhou, Y.; Zhang, Y.; Mahan, H. Assessing agricultural drought in summer over Oklahoma Mesonet sites using the water-related vegetation index from MODIS. Int. J. Biometeorol. 2017, 61, 377-390. [CrossRef]

8. Zhou, Y.; Xiao, X.; Zhang, G.; Wagle, P.; Bajgain, R.; Dong, J.; Jin, C.; Basara, J.B.; Anderson, M.C.; Hain, C.; et al. Quantifying agricultural drought in tallgrass prairie region in the U.S. Southern Great Plains through analysis of a water-related vegetation index from MODIS images. Agric. For. Meteorol. 2017, 246, 111-122. [CrossRef]

9. Nam, W.H.; Choi, J.Y.; Yoo, S.H.; Engel, B.A. A real-time online drought broadcast system for monitoring soil moisture index. KSCE J. Civ. Eng. 2012, 16, 357-365. [CrossRef]

10. Nam, W.H.; Hayes, M.J.; Svoboda, M.D.; Tadesse, T.; Wilhite, D.A. Drought hazard assessment in the context of climate change for South Korea. Agric. Water Manag. 2015, 160, 106-117. [CrossRef]

11. Wilhite, D.A.; Glantz, M.H. Understanding the drought phenomenon: The role of definitions. Water Int. 1985, 10, 111-120. [CrossRef]

12. Nam, W.H.; Tadesse, T.; Wardlow, B.D.; Hayes, M.J.; Svoboda, M.D.; Hong, E.M.; Pachepsky, Y.A.; Jang, M.W. Developing the vegetation drought response index for South Korea (VegDRI-SKorea) to assess the vegetation condition during drought events. Int. J. Remote Sens. 2018, 39, 1548-1574. [CrossRef]

13. Svoboda, M.; LeComte, D.; Hayes, M.; Heim, R.; Gleason, K.; Angel, J.; Rippey, B.; Tinker, R.; Palecki, M.; Stooksbury, D.; et al. The drought monitor. Bull. Am. Meteor. Soc. 2002, 83, 1181-1190. [CrossRef]

14. Groten, S.M.E. NDVI-crop monitoring and early yield assessment of Burkina Faso. Int. J. Remote Sens. 1993, 14, 1495-1515. [CrossRef]

15. Quarmby, N.A.; Milnes, M.; Hindle, T.L.; Silleos, N. The use of multi-temporal NDVI measurements from AVHRR data for crop yield estimation and prediction. Int. J. Remote Sens. 1993, 14, 199-210. [CrossRef]

16. Gitelson, A. Remote sensing estimation of crop biophysical characteristics at various scales. In Hyperspectral Remote Sensing of Vegetation; Thenkabail, P.S., Lyon, J.G., Huete, A., Eds.; CRC Press: Boca Raton, FL, USA, 2012. 
17. Berger, A.; Ettlin, G.; Quincke, C.; Rodríguez-Bocca, P. Predicting the normalized difference vegetation index (NDVI) by training a crop growth model with historical data. Comput. Electron Agric. 2018, 1-7. [CrossRef]

18. Gao, B.C.; Li, R.R. Quantitative improvement in the estimates of NDVI values from remotely sensed data by correcting thin cirrus scattering effects. Remote Sens. Environ. 2000, 74, 494-502. [CrossRef]

19. Fang, H.; Liang, S.; Hoogenboom, G. Integration of MODIS LAI and vegetation index products with the CSM-CERESMaize model for corn yield estimation. Int. J. Remote Sens. 2011, 32, 1039-1065. [CrossRef]

20. Kogan, F.N. Application of vegetation index and brightness temperature for drought detection. Adv. Space Res. 1995, 11, 91-100. [CrossRef]

21. Seiler, R.A.; Kogan, F.; Sullivan, J. AVHRR-Based vegetation and temperature condition indices for drought detection in Argentina. Adv. Space Res. 1998, 21, 481-484. [CrossRef]

22. Tadesse, T.; Senay, G.B.; Berhan, G.; Regassa, T.; Beyene, S. Evaluating a satellite-based seasonal evapotranspiration product and identifying its relationship with other satellite derived products and crop yield: A case study for Ethiopia. J. Appl. Meteorol. Climatol. 2015, 40, 39-54. [CrossRef]

23. Wardlow, B.D.; Egbert, S.L.; Kastens, J.H. Analysis of time-series MODIS 250m vegetation index data for crop classification in the U.S. central great plains. Remote Sens. Environ. 2007, 108, 290-310. [CrossRef]

24. Otkin, J.A.; Anderson, M.C.; Hain, C.; Mladenova, I.E.; Basara, J.B.; Svoboda, M. Examining rapid onset drought development using the thermal infrared-based Evaporative Stress Index. J. Hydrometeorol. 2013, 14, 1057-1074. [CrossRef]

25. Anderson, M.C.; Hain, C.; Wardlow, B.; Pimstein, A.; Mecikalski, J.R.; Kustas, W.P. Valuation of drought indices based on thermal remote sensing of evapotranspiration over the continental United States. J. Clim. 2011, 24, 2025-2044. [CrossRef]

26. Allen, R.; Periera, L.; Raes, D.; Smith, M. Crop Evapotranspiration, Guidelines for Computing Crop Water Requirements -FAO Irrigation and Drainage Paper 56; Food and Agricultural Organization of the United Nations: Rome, Italy, 1998.

27. Anderson, M.C.; Hain, C.R.; Otkin, J.A.; Zhan, X.; Mo, K.C.; Svoboda, M.; Wardlow, B.; Pimstein, A. An intercomparison of drought indicators based on thermal remote sensing and NLDAS-2 simulations with U.S. drought monitor classifications. J. Hydrometeorol. 2013, 14, 1035-1056. [CrossRef]

28. Anderson, M.C.; Zolin, C.A.; Hain, C.R.; Semmens, K.; Yilmaz, M.T.; Gao, F. Comparison of satellite-derived LAI and precipitation anomalies over Brazil with a thermal infrared-based Evaporative Stress Index for 2003-2013. J. Hydrometeorol. 2015, 526, 287-302. [CrossRef]

29. Anderson, M.C.; Zolin, C.A.; Sentelhas, P.C.; Hain, C.R.; Semmens, K.; Yilmaz, M.T.; Gao, F.; Otkin, J.A.; Tetrault, R. The Evaporative Stress Index as an indicator of agricultural drought in Brazil: An assessment based on crop yield impacts. Remote Sens. Environ. 2016, 174, 82-99. [CrossRef]

30. Anderson, M.C.; Norman, J.M.; Mecikalski, J.R.; Otkin, J.A.; Kustas, W.P. A climatological study of evapotranspiration and moisture stress across the continental U.S. based on thermal remote sensing: 1. Model formulation. J. Geophys. Res. Atmos. 2007, 112, D10117. [CrossRef]

31. Norman, J.M.; Kustas, W.P.; Humes, K.S. A two-source approach for estimating soil and vegetation energy fluxes from observations of directional radiometric surface temperature. Agric. For. Meteor. 1995, 77, 263-293. [CrossRef]

32. Otkin, J.A.; Zhong, Y.; Lorenz, D.; Anderson, M.C.; Hain, C. Exploring seasonal and regional relationships between the Evaporative Stress Index and surface weather and soil moisture anomalies across the United States. Hydrol. Earth Syst. Sci. 2018, 22, 5373-5386. [CrossRef]

33. Yang, Y.; Anderson, M.C.; Gao, F.; Wardlow, B.; Hain, C.R.; Otkin, J.A.; Alfieri, J.; Yang, Y.; Sun, L.; Dulaney, W. Field-scale mapping of evaporative stress indicators of crop yield: An application over Mead, NE, USA. Remote Sens. Environ. 2018, 210, 387-402. [CrossRef]

34. Kogan, F.N. Global drought watch from space. Bull. Am. Meteor. Soc. 1997, 78, 621-636. [CrossRef]

35. Kogan, F.N. Operational space technology for global vegetation assessment. Bull. Am. Meteor. Soc. 2001, 82, 1949-1964. [CrossRef]

36. Kogan, F. World droughts in the new millennium from AVHRR-based vegetation health indices. Eos. Trans. Am. Geophys. Union. 2002, 83, 557-563. [CrossRef]

37. Watson, D.J. Comparative physiological studies in the growth of field crops. I. Variation in net assimilation rate and leaf area between species and varieties, and within and between years. Ann. Bot. 1947, 11, 41-76. [CrossRef] 
38. Chen, J.M.; Black, T.A. Defining leaf-area index for non-flat leaves. Plant Cell Environ. 1992, 15, 421-429. [CrossRef]

39. Bolstad, P.V.; Gower, S.T. Estimation of leaf area index in fourteen southern Wisconsin forest stands using a portable radiometer. Tree Physiol. 1990, 7, 115-124. [CrossRef]

40. Smith, N.J. Predicting radiation attenuation in stands of douglas-fir. For. Sci. 1991, 37, 1213-1223.

41. Myneni, R.B.; Ramakrishna, R.; Nemani, R.R.; Running, S.W. Estimation of global leaf area index and absorbed par using radiative transfer models. IEEE Trans. Geosci. Remote Sens. 1997, 35, 1380-1393. [CrossRef]

42. Chen, J.M.; Black, T.A.; Adams, R.S. Evaluation of hemispherical photography for determining plant area index and geometry of a forest stand. Agric. For. Meteorol. 1991, 56, 129-143. [CrossRef]

43. Fassnacht, K.S.; Gower, S.T.; Norman, J.M.; McMurtrie, R.E. A comparison of optical and direct methods for estimating foliage surface area index in forests. Agric. For. Meteorol. 1994, 71, 183-207. [CrossRef]

44. Stenberg, P.; Linder, S.; Smolander, H.; Flowerellis, J. Performance of the lai-2000 plant canopy analyzer in estimating leaf-area index of some scots pine stands. Tree Physiol. 1994, 14, 981-995. [CrossRef] [PubMed]

45. Knyazikhin, Y.; Glassy, J.; Privette, J.L.; Tian, Y.; Lotsch, A.; Zhang, Y.; Wang, Y.; Morisette, J.T.; Votava, P.; Myneni, R.B.; et al. MODIS Leaf Area Index (LAI) and Fraction of Photosynthetically Active Radiation Absorbed by Vegetation (FPAR) product (MOD15). Algorithm Theor. Basis Doc. 1999. Available online: https://modis.gsfc.nasa.gov/data/atbd/atbd_mod15.pdf (accessed on 17 December 2019).

46. Huete, A.; Didan, K.; van Leeuwen, W.; Miura, T.; Glenn, E. MODIS vegetation indices. In Land Remote Sensing and Global Environmental Change: NASA's Earth Observing System and the Science of ASTER and MODIS; Springer-Verlag: New York, NY, USA, 2008; pp. 579-602.

47. Huete, A.; Didan, K.; Miura, T.; Rodriguez, E.P.; Gao, X.; Ferreira, L.G. Overview of the radiometric and biophysical performance of the MODIS vegetation indices. Remote Sens. Environ. 2002, 83, 195-213. [CrossRef]

48. Rowhani, P.; Linderman, M.; Lambin, E.F. Global interannual variability in terrestrial ecosystems: Sources and spatial distribution using MODIS-derived vegetation indices, social and biophysical factors. Int. J. Remote Sens. 2011, 32, 5393-5411. [CrossRef]

49. Liu, H.Q.; Huete, A.R. A feedback based modification of the NDVI to minimize canopy background and atmospheric noise. IEEE Geosci. Remote Sens. 1995, 33, 457-465. [CrossRef]

50. Reed, B.C.; Schwartz, M.D.; Xiao, X. Remote sensing phenology: Status and the way forward. In Phenology of Ecosystem Processes: Applications in Global Change Research; Noormets, A., Ed.; Springer-Verlag: New York, NY, USA, 2009; pp. 231-246.

51. Mun, Y.S.; Nam, W.H.; Jeon, M.G.; Kim, T.G.; Hong, E.M.; Hayes, M.J.; Tadesse, T. Application of meteorological drought index using Climate Hazards Group InfraRed Precipitation with Station (CHIRPS) based on global satellite-assisted precipitation products in Korea. J. Korean Soc. Agric. Eng. 2019, 61, 1-11.

52. Deng, G.; Zhang, H.; Guo, X.; Ying, H. Assessment of drought in Democratic People's Republic of Korea in 2017 using TRMM data. In Proceedings of the 2018 Fifth International Workshop on Earth Observation and Remote Sensing Applications (EORSA), Xi'an, China, 18-20 June 2018.

(C) 2020 by the authors. Licensee MDPI, Basel, Switzerland. This article is an open access article distributed under the terms and conditions of the Creative Commons Attribution (CC BY) license (http://creativecommons.org/licenses/by/4.0/). 